\title{
EKSPLORASI JENIS - JENIS ZINGIBERACEAE DI CAGAR ALAM RAYA PASI GUNUNG POTENG KOTA SINGKAWANG KALIMANTAN BARAT
}

\author{
(Exploration Of Types Of Zingiberaceae In Cagar Alam Raya Pasi Poteng Mountain \\ Singkawang, West Borneo)
}

\author{
Mahmudi, M. Sofwan Anwari, Wahdina \\ Fakultas Kehutanan Universitas Tanjungpura Jl. Daya Nasional, Pontianak 78124 \\ Email: cingmachmud@gmail.com
}

\begin{abstract}
Pasi Nature Reserve of Poteng Mount includes tropical forest type and has many biological diversities, one of them is Zingiberaceae family. Research on the potential of Zingiberaceae in Nature Reserve Poteng Mount Pasi area has never been done, therefore it is necessary to research the types of Zingiberaceae species available in this location. The purpose of this research is to know the types of zingiberaceae in Mount Poteng, and its benefits can provide data and information about the types of Zingiberaceae. This research was conducted on December 23, 2016. The method used is the exploration method and the collection of flora, by exploring every angle of the study sites that can represent the types of habitat or vegetation in the area. The results are 9 species of 7 genus with a total of 37 individuals were found. 1 species of genus Alpinia, 1 species of genus Etlingera, 1 species of genus Globa, 1 species of genus Hedychium, 2 species of genus Hornstedtia, 1 species of genus Scaphoclamys and 2 species of genus Zingiber.
\end{abstract}

Keywords: Exploration, Mount Poteng, Zingiberaceae

\section{PENDAHULUAN}

Zingiberaceae adalah tumbuhan berbunga yang secara umum dikenal oleh masyarakat Indonesia sebagai tanaman Jahe-jahean. Famili Zingiberaceae merupakan suku terbesar dari ordo Zingiberales dan ada sekitar 53 genera dengan lebih 1.500 spesies di seluruh dunia, sebagian besar dari jumlah tersebut terdapat di hutan tropis. Tumbuhan ini banyak dimanfaatkan antara lain sebagai bumbu masak, obat-obatan bahan rempahrempah, bahan kosmetik, bahan minuman, dan sebagainya (Lawrence, 1964).

Zingiberaceae salah satu tumbuhan yang banyak ditemukan pada kawasan hutan tropis, terutama Indo-Malaya. Menurut Pandey (2003), terdapat sekitar $50 \%$ dari total genera famili Zingiberaceae ini ditemukan di hutan tropis dan dapat hidup di hutan dataran rendah sampai pada ketinggian lebih kurang dari $2000 \mathrm{~m}$ dpl terutama pada daerah dengan curah hujan yang tinggi. Sejauh ini negara yang kaya akan jenis - jenis Zingiberaceae adalah Indonesia, Malaysia, Brunei, Singapura, Thailand, dan Filipina. Pulau yang luas di Indonesia seperti Sumatera dan Kalimantan masih belum banyak diketahui lebih dalam lagi tentang keanekaragaman jenis jahe ini. Lamb (2013), menyatakan bahwa di Pulau Kalimantan famili Zingiberaceae memiliki 19 genera dengan 250 jenis dan masih banyak yang belum dideskripsikan sebagai jenis baru. Oleh karena itu banyak jenis baru yang dipastikan dapat ditemukan kembali (Larsen, 1999). Kalimantan yang termasuk bagian Indonesia belum banyak 
dilakukan penelitian mengenai keanekaragaman jenis $\quad-\quad$ jenis Zingiberaceae.

Cagar Alam Raya Pasi Gunung Poteng temasuk dalam tipe hutan hujan tropis dan banyak memiliki keanekaragaman hayati yang bervariasi, salah satunya adalah famili Zingiberaceae. Penelitian mengenai potensi kekayaan jenis-jenis Zingiberaceae di kawasan Cagar Alam Raya Pasi Gunung Poteng belum pernah dilakukan, untuk itu dengan adanya penelitian ini diharapkan bisa menambah informasi mengenai jenis - jenis Zingiberaceae yang ada di Cagar Alam Raya Pasi Gunung Poteng..

\section{METODE PENELITIAN}

Penelitian ini dilakukan dengan menggunakan metode eksplorasi dan koleksi flora. Penelitian dilakukan dengan cara menjelajahi setiap sudut lokasi penelitian yang dapat mewakili tipe-tipe habitat ataupun vegetasi di kawasan yang diteliti (Rugayah, 2004).

Jalur eksplorasi akan dibuat sebanyak 6 jalur pengamatan dengan masing-masing jalur memiliki panjang 500 meter dan jangkauan lebar 20 meter (10 meter ke kanan dan 10 meter ke kiri dari sumbu jalur). Jalur diletakan secara sengaja (purposive) pada masing-masing kondisi di lapangan yaitu hutan primer (dua jalur), hutan sekunder (dua jalur), dan pinggiran sungai (dua jalur). Semua jenis Zingiberaceae yang dijumpai pada lokasi penelitian diambil titik koordinat, dokumentasi beserta sampel herbariumnya, setiap jenis yang dikoleksi terlebih dahulu diberi nomor koleksi dan dicatat informasi lapanganya.
Teknik pengambilan data ada dua yaitu data primer dan data sekunder. Data primer dalam penelitian ini yaitu data yang diperoleh langsung di lokasi penelitian berupa ciri morfologi, nama ilmiah dan lokal, habitat, ketinggian tempat, titik koordinat, nomor koleksi dan tanggal pengamatan. Pencatatan tersebut dilakukan pada semua jenis dari famili Zingiberaceae yang ditemui di lokasi penelitian. Data sekunder yang dibutuhkan sebagai penunjang penelitian di lapangan yaitu keadaan umum lokasi penelitian, geologi tanah, literatur serta data lain yang dapat membantu dalam penelitian ini.

Kemudian analisis data dilakukan dengan cara pencatatan semua jenis famili Zingiberaceae yang ditemui dalam lokasi penelitian berupa ciri-ciri morfologi, yang di catat ke dalam tally sheet pengamatan. Data di lapangan digunakan sebagai bahan utama untuk melakukan identifikasi jenis, kemudian dimasukan ke dalam daftar jenis yang ditulis menggunakan nama ilmiah sesuai aturan Binominal Nomenclature dan penulisan dikelompokan berdasarkan genus atau marga masing-masing. Setiap titik koordinat data sebaran tiap jenis famili Zingiberaceae yang ditemui di lapangan akan ditampilkan dalam peta.

\section{HASIL DAN PEMBAHASAN}

Hasil pengamatan di lapangan pada enam jalur jelajah dengan tiga tipe habitat yaitu, hutan sekunder, hutan primer dan pinggiran sungai mendapatkan jenis - jenis yang bervariasi. Setelah melalui proses identifikasi ditemukan sembilan jenis Zingiberaceae yang tergolong ke dalam tujuh genus yang berbeda. Pada jalur pertama ditemukan dua jenis dari dua 
genus yang berbeda, jalur kedua ditemukan

3 jenis dari 2 genus yang berbeda, jalur ketiga ditemukan 3 jenis dari 2 genus yang berbeda, jalur keempat ditemukan 1 jenis dari 1 genus, jalur kelima ditemukan 3 jenis dari 3 genus berbeda, dan jalur keenam ditemukan 3 jenis dari 3 genus berbeda.

Tabel 1. Daftar jenis Zingiberaceae yang ditemukan dari semua jalur di Cagar Alam Raya Pasi. Gunung Poteng

\begin{tabular}{|c|c|c|c|}
\hline No & Genus & Spesies & Nama Lokal \\
\hline 1 & Alpinia & Alpinia ligulata Odoardo & Lengkuas \\
\hline 2 & Etlingera & Etlingera velutina Ridl. R.M. Sm & Kecombrang \\
\hline 3 & Globa & Globa franciscii Ridl.R.M. Sm & - \\
\hline 4 & Hedychium & Hedychium coranarium lily & Gandasuli \\
\hline 5 & Hornstedtia & $\begin{array}{l}\text { Hornstedtia conica } \text { Ridl } \\
\text { Hornstedtia havilandii } \mathrm{K} \text {. Schum }\end{array}$ & $\begin{array}{l}\text { Pining bawang } \\
\text { Temuireng }\end{array}$ \\
\hline 6 & Scaphoclamys & Scaphochlamys sp & - \\
\hline 7 & Zingiber & $\begin{array}{l}\text { Zingiber acuminatum Var. Borneense Valeton } \\
\text { Zingiber sp }\end{array}$ & Sisik Kuning \\
\hline
\end{tabular}

Hasil penelitian menunjukan jenisjenis yang ditemukan sebanyak sembilan jenis dari tujuh genus dengan jumlah total sebanyak 37 individu. Genus Alpinia yang ditemukan pada lokasi penelitian ini ditemukan jenis Alpinia ligulata Odoardo. Jenis Alpinia ligulata Odoardo ini banyak ditemukan pada daerah yang tertutup atau ternaungi dengan intensitas cahaya yang cukup. Menurut Larsen et al (1999)) menyatakan bahwa secara alami alpinia tumbuh mengelompok di tempat-tempat lembab, hutan sekunder atau lokasi hutan yang terbuka. Jenis Alpinia ligulata Odoardo ciri utamanya tampak sama dengan Alpinia nieuwenhuizii Valeton namun jenis Alpinia ligulata Odoardo memiliki buah yang warna coraknya kehijauan dan pembungaanya lebih sedikit. Pusat penyebaran dari genus Alpinia tersebar di daerah tropis sampai ke sebelah utara equator.
Genus Etlingera yang ditemukan dilokasi penelitian yaitu jenis Etilingera velutina Ridl. R.M. Sm. Jenis genus ini banyak ditemukan di jalur satu dan dua di tepi aliran sungai pada daerah yang lembab dan tertutup dengan intensitas cahaya yang cukup dikarenakan pada saat pengambilan data Genus Etlingera tidak ditemukan jenis ini di tempattempat terbuka dengan intensitas cahaya matahari tinggi. Menurut Larsen et al (1999) dalam Nurainas \& Yunaidi (2007) menyatakan secara alami Etlingera tumbuh mengelompok di tempat-tempat lembab yang dekat dengan aliran sungai dengan vegetasi yang cukup rapat.

Genus Globba yang ditemukan pada lokasi penelitian di lapangan yaitu jenis Globa franciscii Ridl.R.M. Sm. Genus ini dijumpai pada daerah - daerah yang lembab di sekitar pinggiran sungai dan tumbuh di tengah bebatuan kecil pada bibir sungai dengan ketinggian 400 
mdpl. Menurut Van Valkenburg 7 Bunyapraphatsara (2002), genus ini dapat tumbuh dari daerah rendah sampai ke daerah yang cukup tinggi, tetapi jenis ini lebih banyak ditemukan di daerah yang lembab dan juga banyak tumbuh di tepi pinggiran sungai.

Genus Hornstedtia yang ditemukan yaitu Hornstedtia conica Ridl, Hornstedtia havilandii K. Schum. Lokasi penelitian jenis ini dijumpai pada daerah - daerah terbuka dengan intensitas cahaya yang cukup tinggi dari ketinggian 200 - 400 mdpl. Ciri khas dari genus Hornstedtia yaitu perbungaannya yang berbentuk kumparan dilapisi oleh berlapis-lapis braktea yang kompak yang menjadi pembeda yang jelas dengan genus lainnya (Nurainas et al, 2011).

Genus Hedychium yang ditemukan yaitu Hedychium coranarium lily, tanaman ini biasanya berada pada daerah yang lembab. Tanaman kecil ini memiliki ukuran 1,5-2 m. tanaman gandasuli memliliki helaian daun berbentuk runcing dengan panjang 7-55 $\mathrm{cm}$ dengan lebar 3-5 $\mathrm{cm}$. batang pada genus Hedychium melingkar di penampang kuat, tidak bercabang , kemerahan dibawah batang dan tertutup oleh lembar daun, satu untuk setiap ruas. Bunga pada genus ini umumnya berwarna putih dan berbau wangi.

Genus Zingiber yang ditemukan dilokasi penelitian yaitu, Zingiber acuminatum var. Borneense Valeton dan Zingiber sp. genus ini merupakan tanaman berukuran sedang, yaitu dengan tinggi tanaman mulai dari $30-180 \mathrm{~cm}$.
Tanaman ini tumbuh tegak dan biasanya memiliki batang semu tebal yang menopang daun berbentuk lanceilate. sebagian besar memiliki periode pembungaan yang singkat dan muncul langsung dari rhizome, tidak jauh dari batang semu. Bunganya berbentuk krucut terkadang berbentuk sangat panjang, terkadang pendek dan tidak cerah. Sebagian besar genus ini memiliki kumpulan breaktea yang tersusun erat. Breakte yang mekar penuh biasanya berwarna kuning.

Dalam pengambilan data di lapangan ada beberapa genus yang hanya memiliki satu jenis yaitu Etlingera valutina Ridl, Globa franciscii Ridl, Hedychium coranarium Lily, Scaphoclamys $S p$, tetapi berdasarkan faktor lingkungan kawasan ini mendukung untuk pertumbuhan Jenis Zingiberaceae. Hal ini disebabkan genus - genus tersebut memiliki kemampuan yang berbeda dibandingkan dengan genus lain untuk hidup dan berkembang dalam suatu kawasan. Loveless (1989) menyatakan bahwa suatu tumbuhan dapat tumbuh dan berkembang dengan baik apabila kebutuhan fisiologi tumbuhan dipenuhi oleh lingkungan.

\section{Kesimpulan}

Berdasarkan penelitian Eksplorasi jenis Zingiberaceae di Gunung Poteng Cagar Alam Raya Pasi Kota Singkawang Kalimantan Barat disimpulkan bahwa:

- Jenis Zingiberaceae ditemukan sebanyak 9 jenis yang tergolong ke dalam 7 genus berbeda.

- Jenis - jenis Zingiberaceae yang ditemukan yaitu, Alpinia ligulata 
Odoardo, Etlingera velutina Ridl. R.M, Globa franciscii Ridl. R.M, Hedychium coranarium Lily, Hornstedtia conica Ridl, Hprstedtia havilandii K. Schum. Scaphochlamys Sp, Zingiber acuninatum var. boernesis Valeton, Zingiber sp

\section{Saran}

Perlu dilakukan penelitian lebih lanjut lagi tentang jenis - jenis Zingiberaceae di kawasan Cagar Alam Raya Pasi Gunung Poteng Kota Singkawang Kalimantan Barat pada musim yang berbeda dengan cakupan yang lebih luas untuk melengkapi data agar lebih lengkap dan akurat.

\section{DAFTAR PUSTAKA}

Lamb, A. 2013. A Guide to Gingers Of Borneo. Natural History Publication (Borneo), Kinabalu

Larsen, K, H. Ibrahim, S. H. Khaws, dan L. G. Saw. 1999. Ginger of Peninsular Malaysia and Singapore. Natural History Publications (Borneo). Kinabalu
Lawrence, G. H. M. 1964. Taxonomy of Vascular Plants. The Macmillan Company. New York.

Nurainas dan Yunaidi. 2007. Panduan Lapangan jahe-jahean liar di Taman Nasional Siberut. Garisatra, Padang.

Nurainas, Syamsuardi, dan A. Arbain. 2011. Distribusi Hornstedtia Retz. Di Sumatera. Universitas Andalas. Padang

Pandey, B. P. 2003. A Textbook of Botany Angiosperm. First Edition, S. Chand \& Company Ltd. Ram Nagar, New Delhi.

Rugayah, Elizabeth, A. Widjaja dan Praptiwi. 2004. Pedoman Pengumpulan Data Keanekaragaman Flora. Cetakan Pertama. Pusat Penelitian BiologiLembaga Ilmu Pengetahuan Indonesia, Bogor.

Van Valkenburg, J. L. C. H. V.\& Bunyapraphatsara, N. 2002. Plant Resources of South East Asia 12. (2). Medical and Poisonous Plant 2. Bogor-Indonesia: Prosea Foundation. Pp. 52-56, 293-294. 